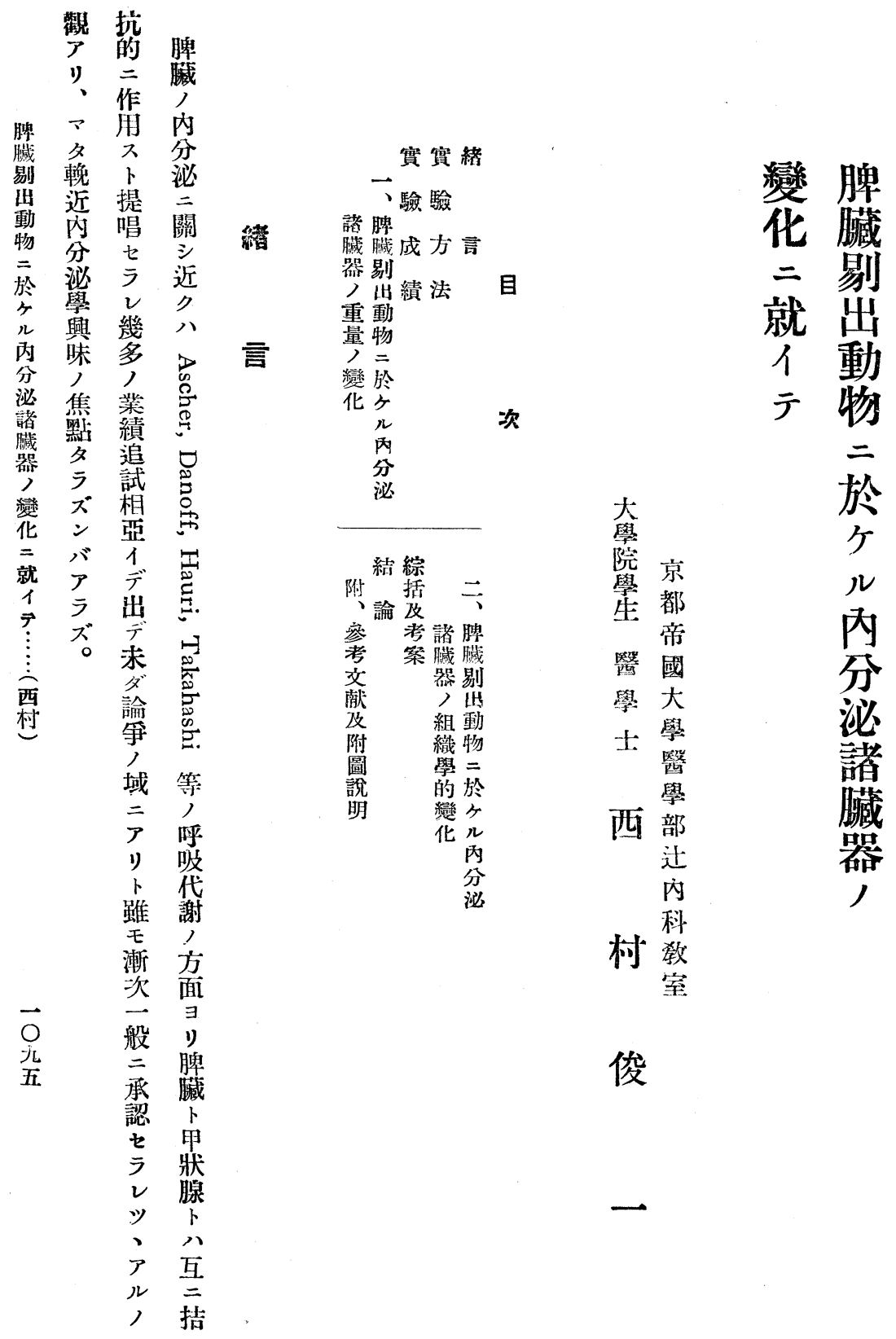




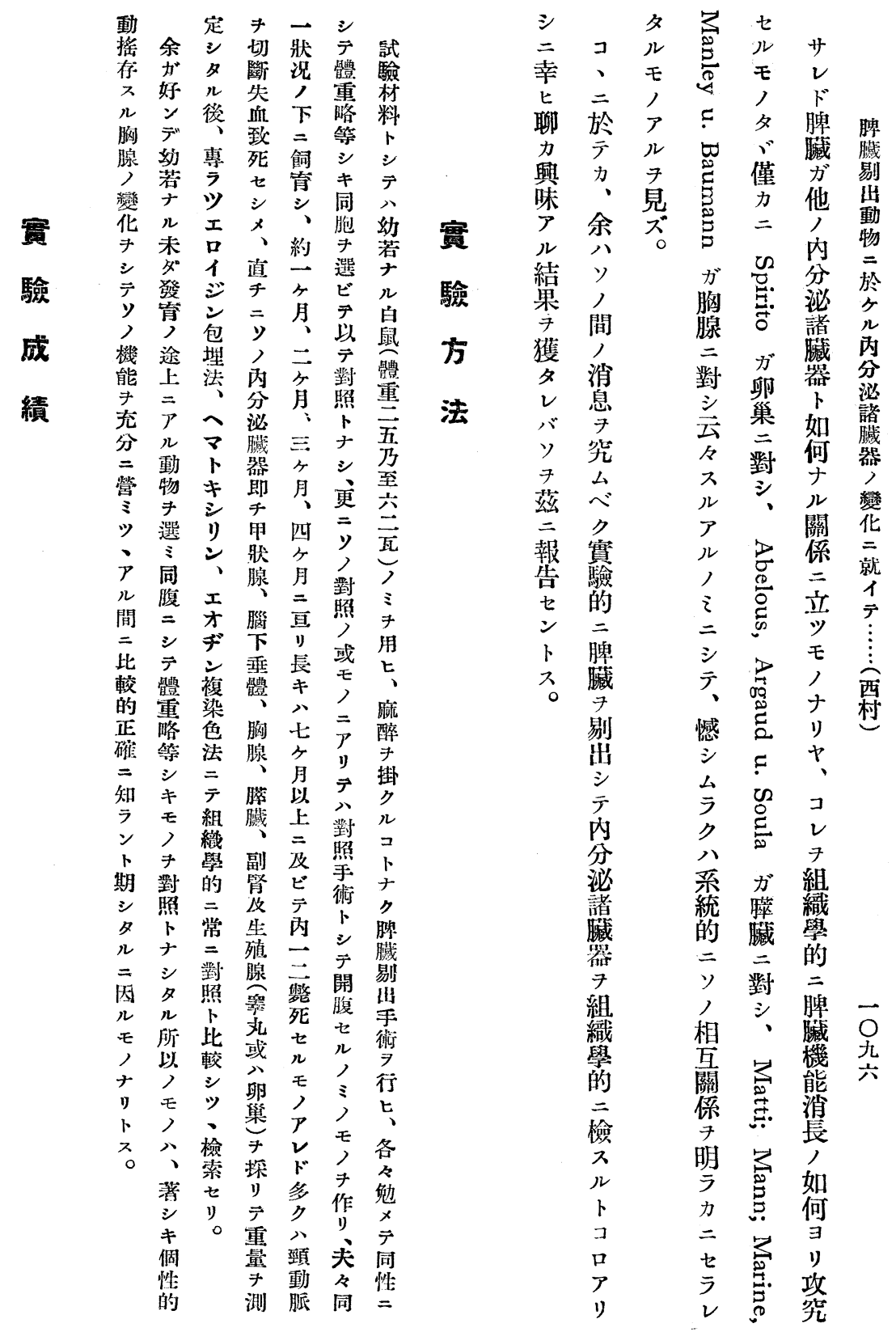




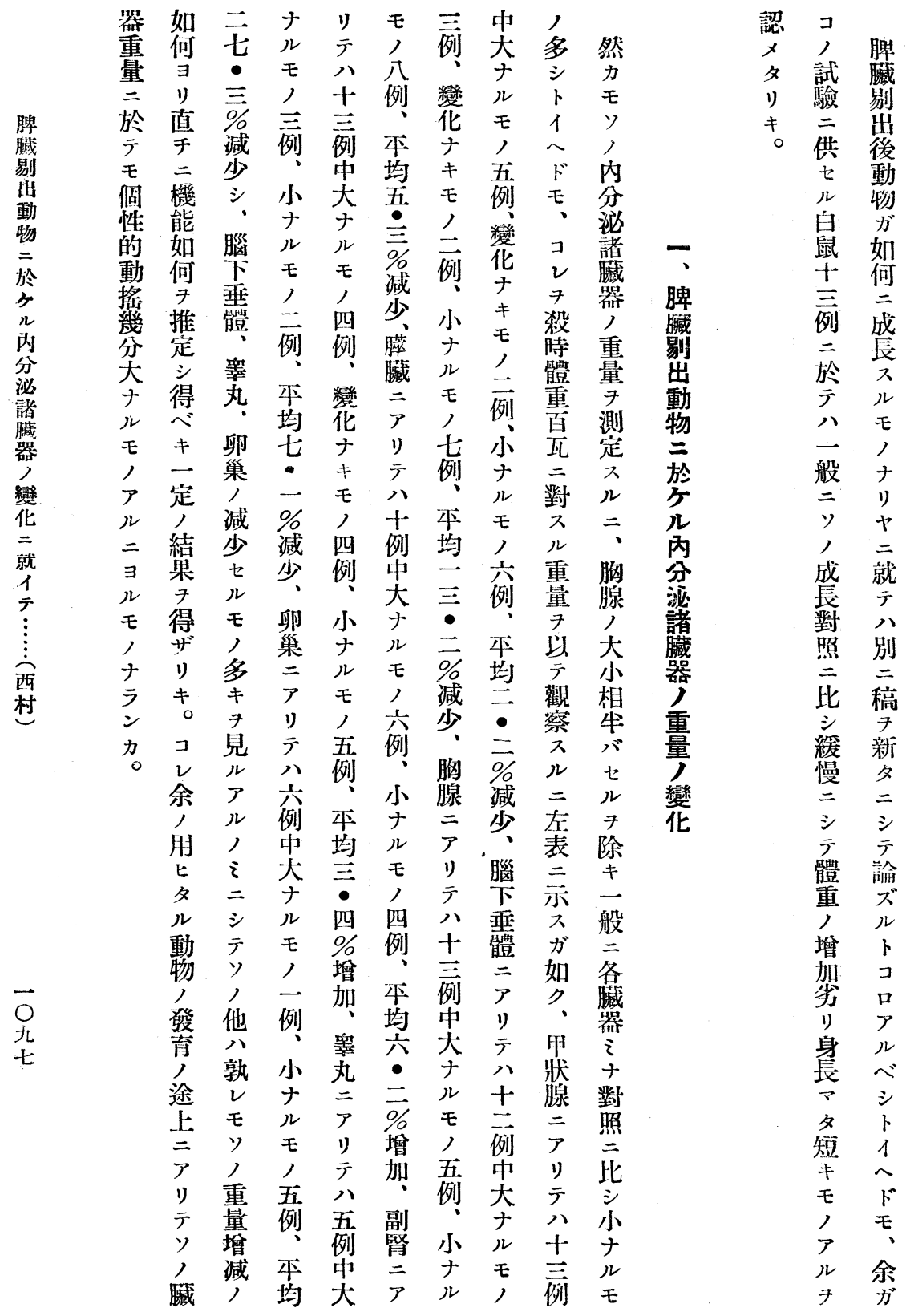




\begin{tabular}{|c|c|c|c|c|c|c|c|c|c|c|c|c|c|c|c|}
\hline 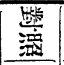 & $\infty$ & $-r$ & 䇾 & $\infty$ & 慗 & r & 踣 & 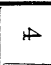 & 敕 & co & 觜 & 10 & 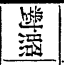 & - & 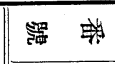 \\
\hline$\rightarrow$ & to & to & $\leftrightarrow \rightarrow$ & 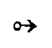 & to & to & to & to & to & to & to & to & $\leftrightarrow \rightarrow$ & $\leftrightarrow$ & 点 \\
\hline 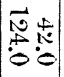 & $\mid \begin{array}{l}\overrightarrow{0} \\
0.4 \\
0 \\
0\end{array}$ & $\begin{array}{l}-1: \\
-1: 0 \\
0\end{array}$ & 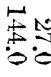 & 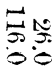 & $\begin{array}{ll}\infty & 0 \\
90 & 0 \\
0 & 0\end{array}$ & 突 & 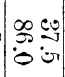 & r & 80 & $\begin{array}{l}1 \\
P \\
=0 \\
=0\end{array}$ & $\begin{array}{l}-100 \\
0.0 \\
0.0\end{array}$ & $\begin{array}{l}1 \\
0 \\
0 \\
0 \\
0 \\
0\end{array}$ & $\begin{array}{ll}0 & 0 \\
0 & 0 \\
0 & 0\end{array}$ & $\mid \begin{array}{c}0 \\
0 \\
0 \\
0 ;\end{array}$ & 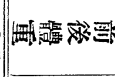 \\
\hline & $\stackrel{\wp}{\dddot{G}}$ & 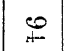 & & $\stackrel{\mathscr{Q}}{\mathrm{O}}$ & & $\stackrel{\oplus}{\circ}$ & & 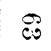 & & 8 & & 恕 & & 8 & 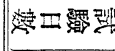 \\
\hline 唁 & 诺 & 제 & 咲 & 譄 & 嚆晨 & 说 & 竳 & 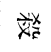 & 㸚关 & 咲 & 坟首 & 䇋 & 就 & 说 & 聮 첨 \\
\hline $\begin{array}{l}8 \\
8 \\
8 \\
8 \\
0\end{array}$ & 怘 & 惫 & : & 离 & : & 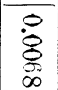 & $\begin{array}{l}0 \\
\dot{8} \\
\end{array}$ & 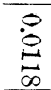 & $\begin{array}{l}0 \\
0 \\
0 \\
0 \\
0 \\
\infty\end{array}$ & 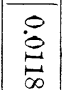 & : & $\begin{array}{l}0 \\
0 \\
8 \\
-1\end{array}$ & $\begin{array}{l}\dot{B} \\
\stackrel{0}{0}\end{array}$ & 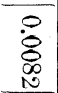 & 覀要 \\
\hline 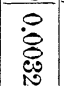 & $\begin{array}{l}8 \\
8 \\
0 \\
0 \\
0\end{array}$ & 1 & 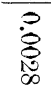 & 8 & $\begin{array}{l}8 \\
8 \\
8\end{array}$ & 8 & $\stackrel{8}{8}$ & 8 & 总 & $\begin{array}{l}\circ \\
:\end{array}$ & 离 & 8 & $\begin{array}{l}8 \\
8 \\
8 \\
10\end{array}$ & $\begin{array}{l}8 \\
8 \\
0 \\
0\end{array}$ & 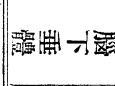 \\
\hline 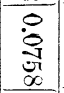 & $\stackrel{0}{ت}$ & $\begin{array}{l}8 \\
8 \\
8 \\
0 \\
0\end{array}$ & $\begin{array}{l}0 \\
6 \\
0 \\
\infty \\
0\end{array}$ & 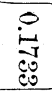 & $\stackrel{8}{\circ}$ & $\stackrel{0}{60}$ & 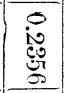 & 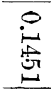 & $\begin{array}{l}0 \\
\text { is } \\
\text { D }\end{array}$ & $\begin{array}{l}8 \\
0 \\
0 \\
0 \\
0 \\
0\end{array}$ & 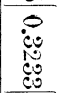 & $\begin{array}{l}8 \\
\text { is } \\
\stackrel{0}{\infty}\end{array}$ & $\begin{array}{l}0 \\
\stackrel{8}{10} \\
\stackrel{i}{0}\end{array}$ & $\dot{b}$ & 涩 要 \\
\hline 1 & 1 & I & 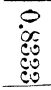 & 范 & $\begin{array}{l}8 \\
0 \\
01 \\
0.0 \\
0.0\end{array}$ & 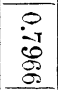 & 1 & 1 & 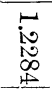 & $\overrightarrow{\vec{B}}$ & 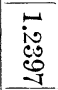 & 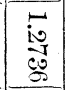 & 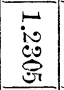 & $\begin{array}{l}\vec{\infty} \\
\infty \\
\infty \\
\infty\end{array}$ & 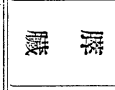 \\
\hline $\begin{array}{l}\mathscr{8} \\
\mathscr{8} \\
8 \\
0\end{array}$ & $\begin{array}{l}8 \\
0 \\
0\end{array}$ & $\stackrel{8}{\stackrel{8}{c}}$ & : & 8 & 惫 & $\begin{array}{l}8 \\
\stackrel{9}{9} \\
\stackrel{9}{10}\end{array}$ & $\begin{array}{l}\stackrel{8}{0} \\
\stackrel{0}{50}\end{array}$ & 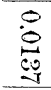 & : & 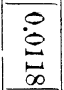 & 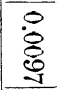 & $\begin{array}{l}8 \\
8 \\
8 \\
8 \\
0\end{array}$ & $\begin{array}{l}\dot{8} \\
\dot{0}\end{array}$ & $\begin{array}{l}\dot{8} \\
\dot{0} \\
\infty \\
0\end{array}$ & 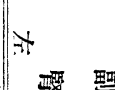 \\
\hline $\begin{array}{l}8 \\
0 \\
0 \\
0\end{array}$ & $\begin{array}{l}8 \\
0 \\
0 \\
0\end{array}$ & 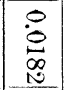 & : & 宮 & $\begin{array}{l}8 \\
\stackrel{8}{g} \\
\end{array}$ & $\begin{array}{l}\text { O } \\
\text { 总 }\end{array}$ & $\begin{array}{l}8 \\
0 \\
\text { 芯 } \\
\end{array}$ & 总 & 圖 & $\stackrel{\stackrel{\leftrightarrow}{\mathscr{B}}}{\stackrel{\infty}{\infty}}$ & 弟 & : & $\begin{array}{l}\dot{0} \\
\dot{0}\end{array}$ & $\begin{array}{l}\dot{0} \\
\dot{0} \\
0 \\
\end{array}$ & \\
\hline 1 & & & 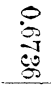 & 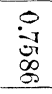 & & & & & & & & & 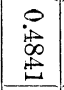 & 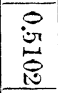 & $\mathrm{N}_{4}$ \\
\hline 1 & & & 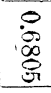 & 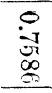 & & & & & & & & & $\begin{array}{l}0 \\
\text { 悹 } \\
0\end{array}$ & 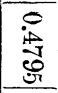 & \\
\hline & 1 & 1 & & & $\begin{array}{l}\circ \\
: \\
0 \\
0\end{array}$ & $\begin{array}{l}8 \\
8 \\
8 \\
8 \\
0\end{array}$ & 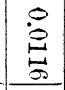 & 总 & $\begin{array}{l}8 \\
\text { 量 } \\
\text { v }\end{array}$ & 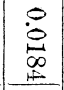 & $\begin{array}{l}0 \\
0 \\
0 \\
0 \\
\infty \\
\infty\end{array}$ & 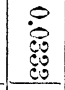 & & & \\
\hline & 1 & 1 & & & 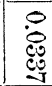 & 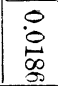 & $\begin{array}{l}\stackrel{8}{0} \\
\stackrel{\leftrightarrow}{A}\end{array}$ & $\begin{array}{l}\circ \\
\stackrel{8}{8} \\
\stackrel{8}{4}\end{array}$ & 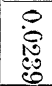 & \begin{tabular}{l}
$:$ \\
$\stackrel{9}{9}$ \\
\hdashline
\end{tabular} & : & $\begin{array}{l}0 \\
0 \\
0 \\
0 \\
0\end{array}$ & & & Dी \\
\hline
\end{tabular}




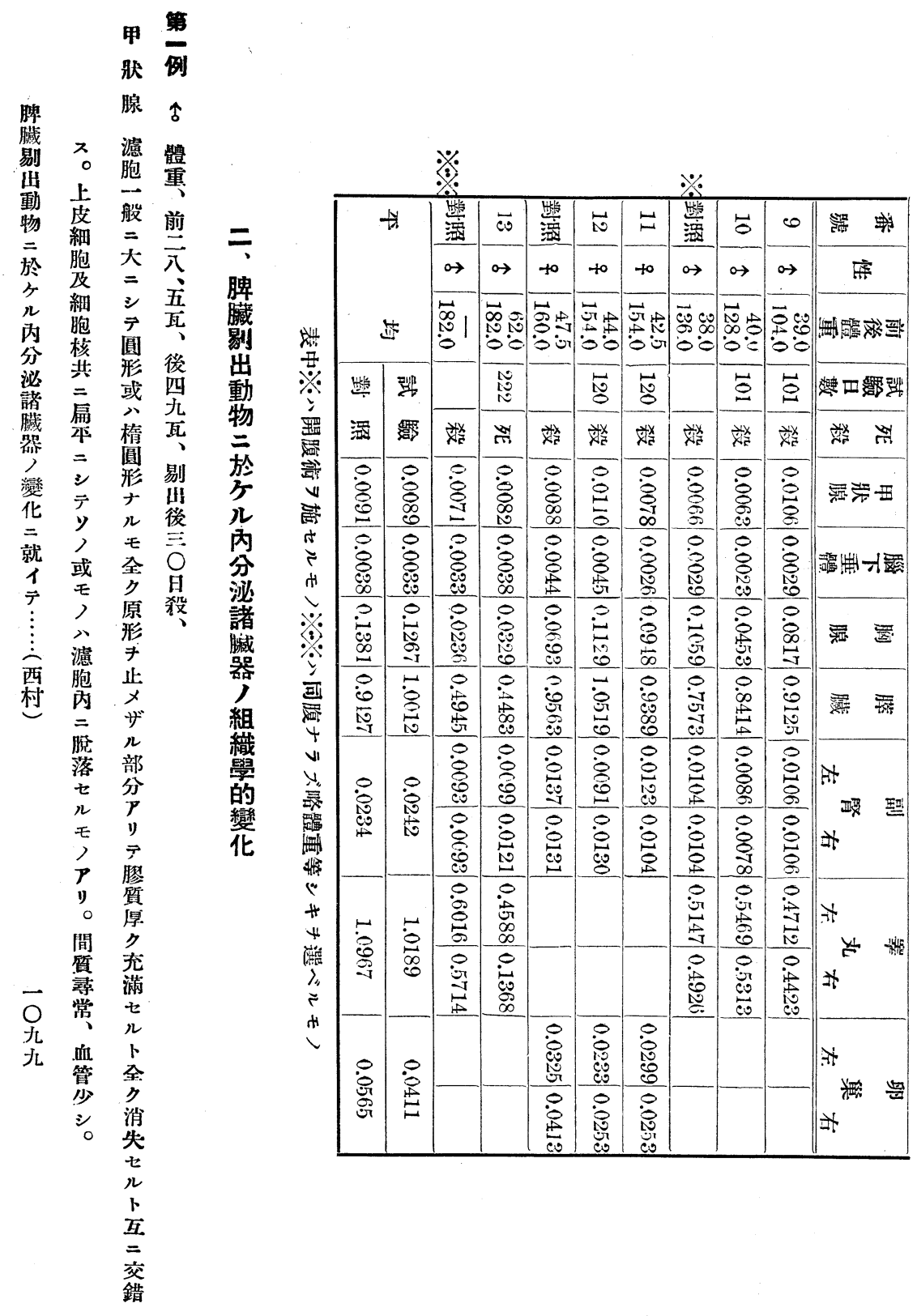




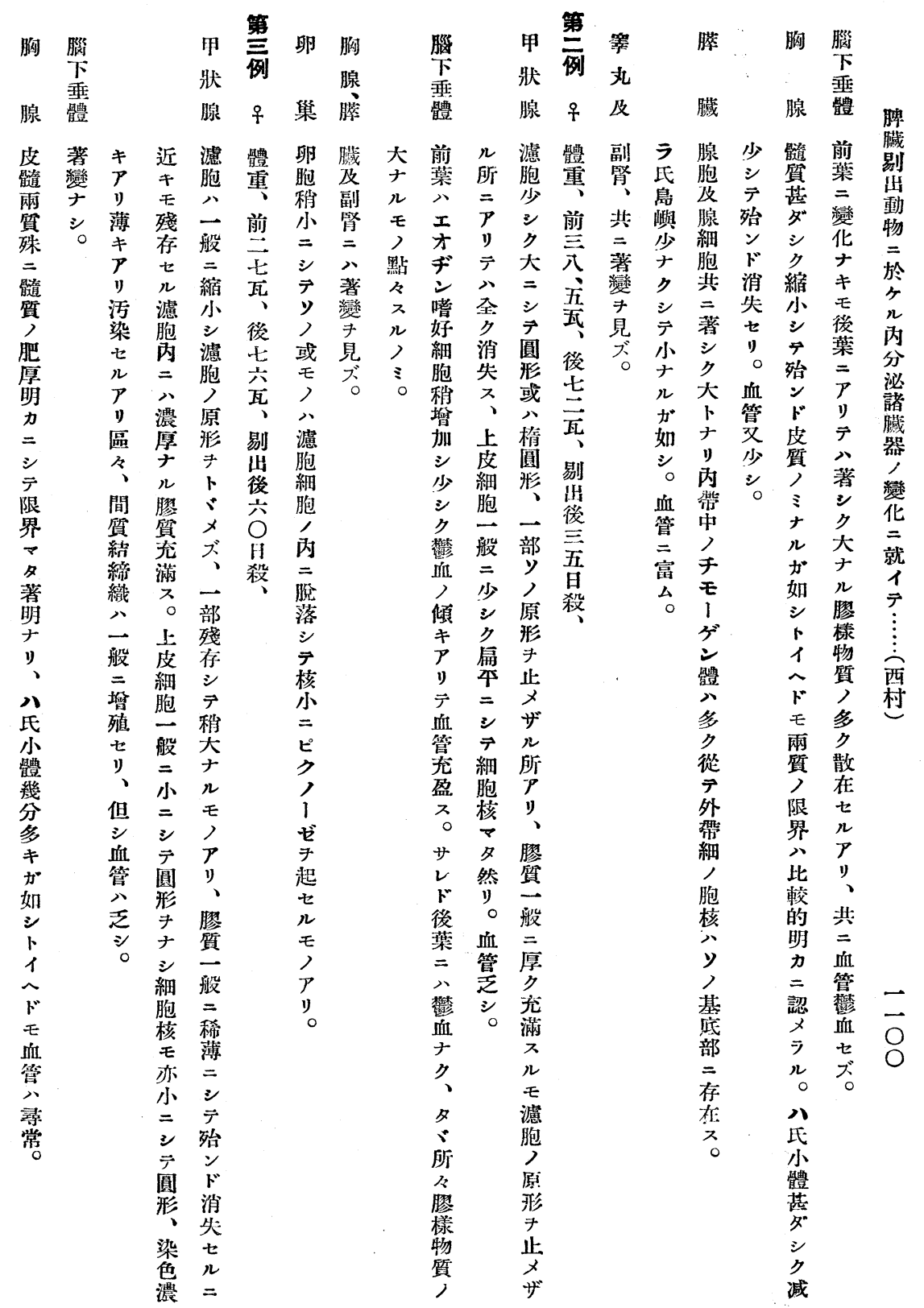




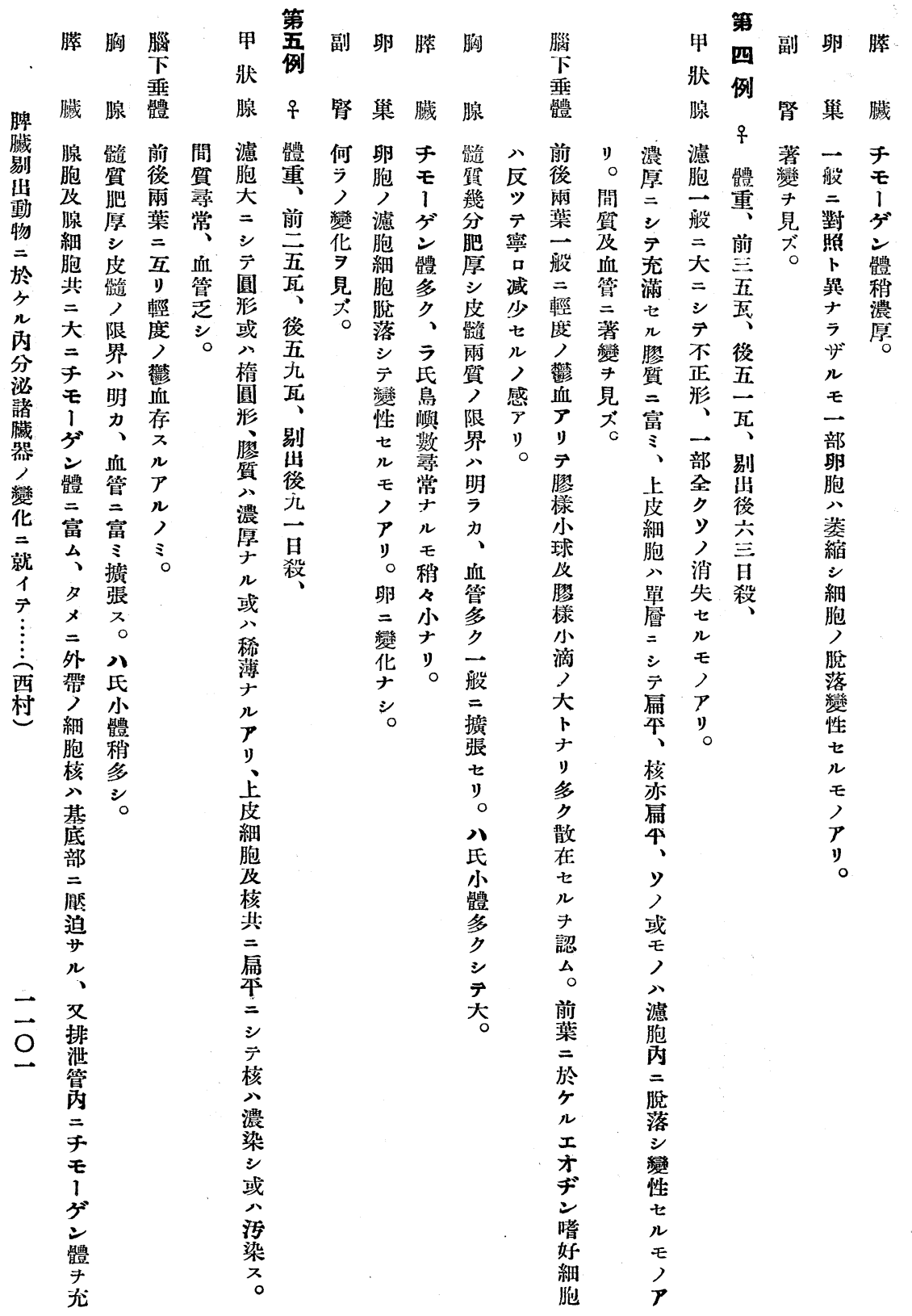




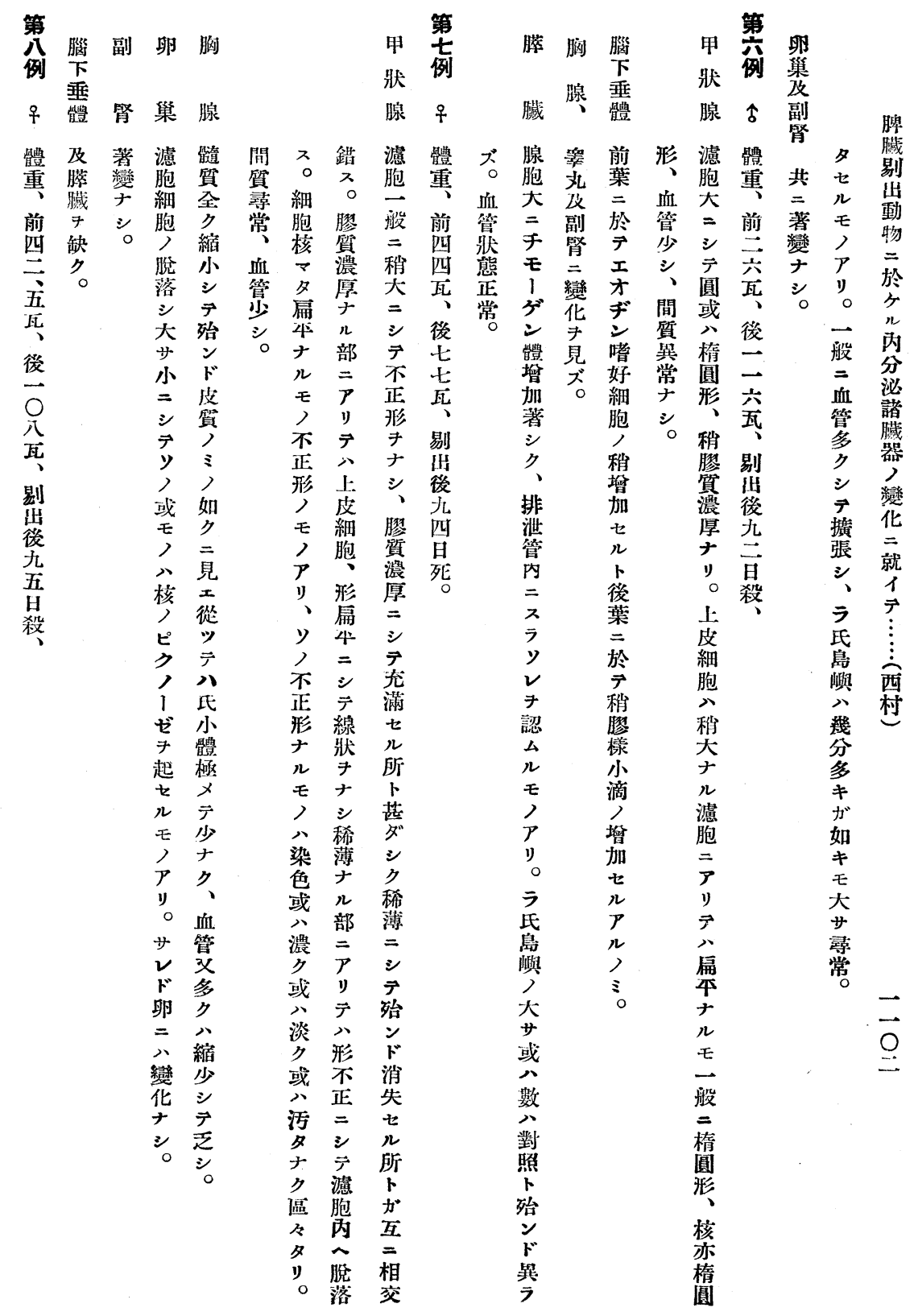




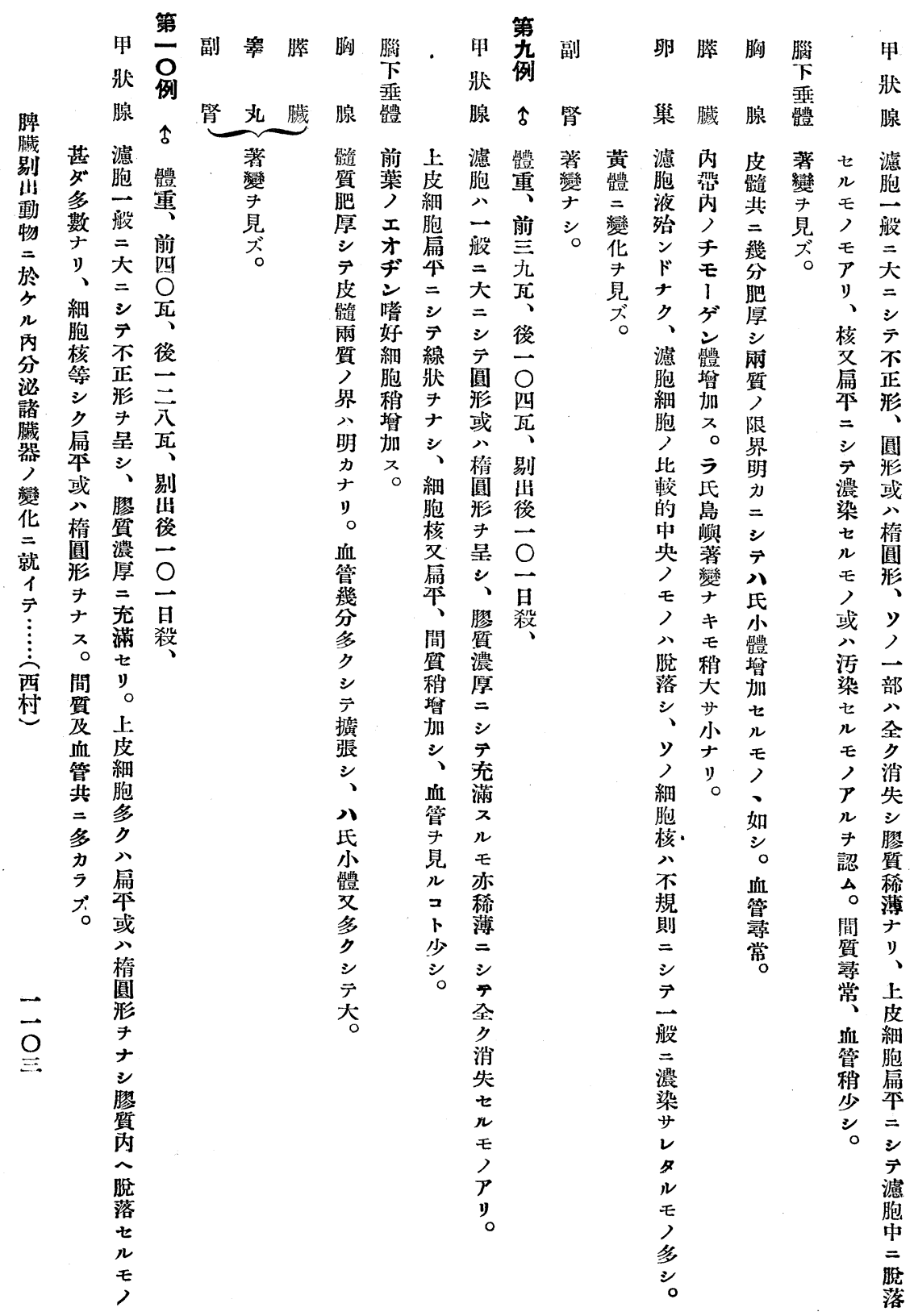




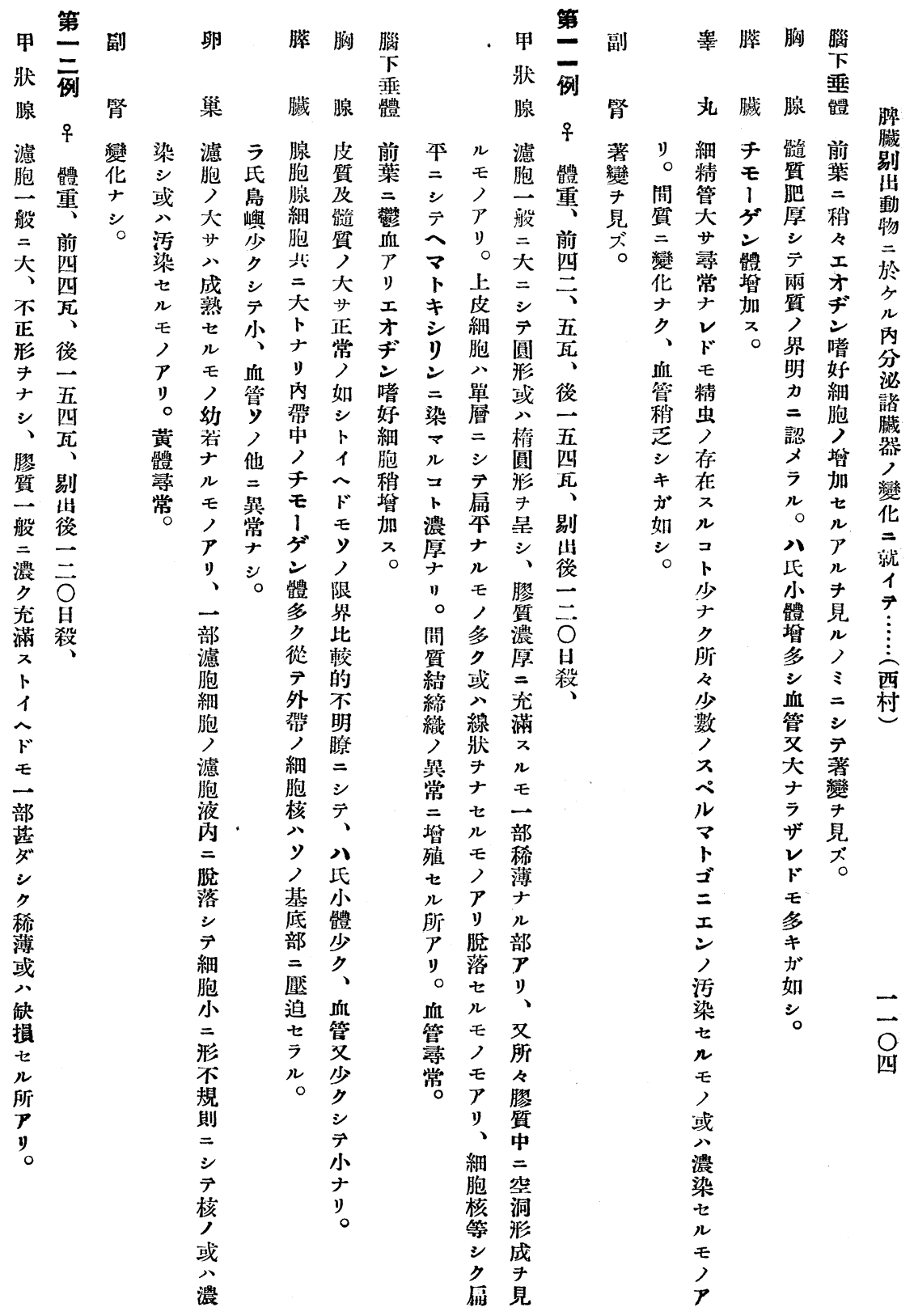




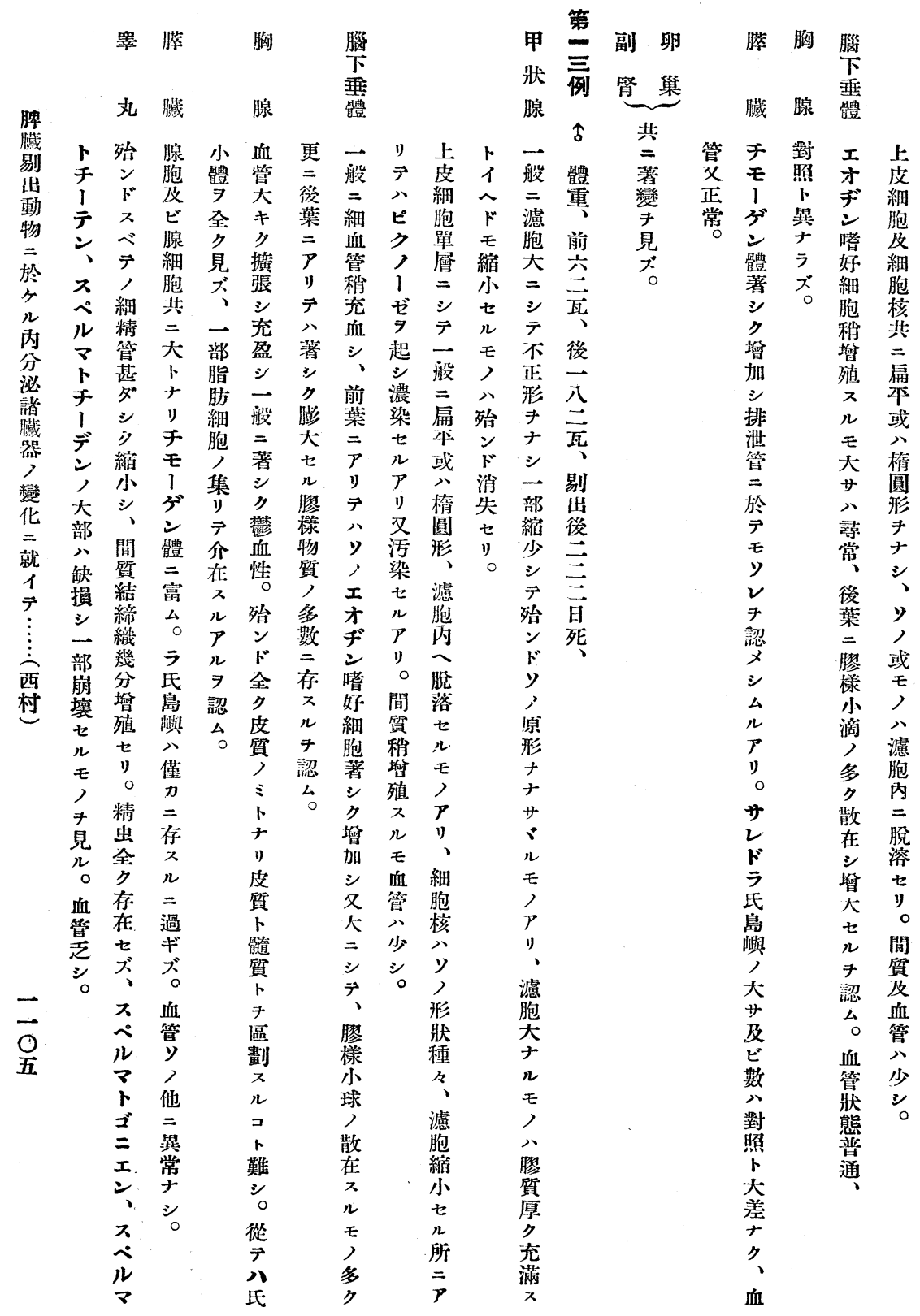




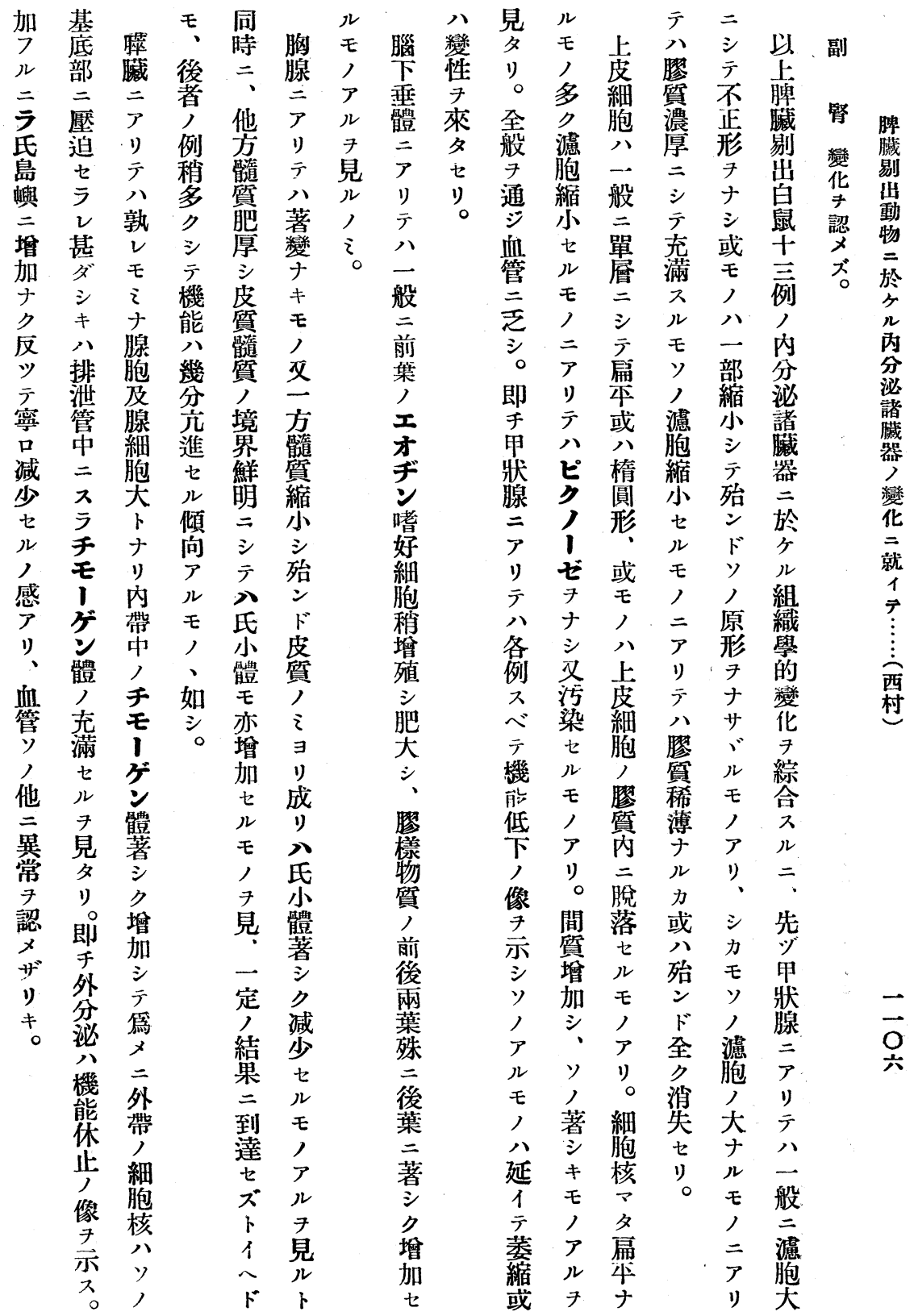




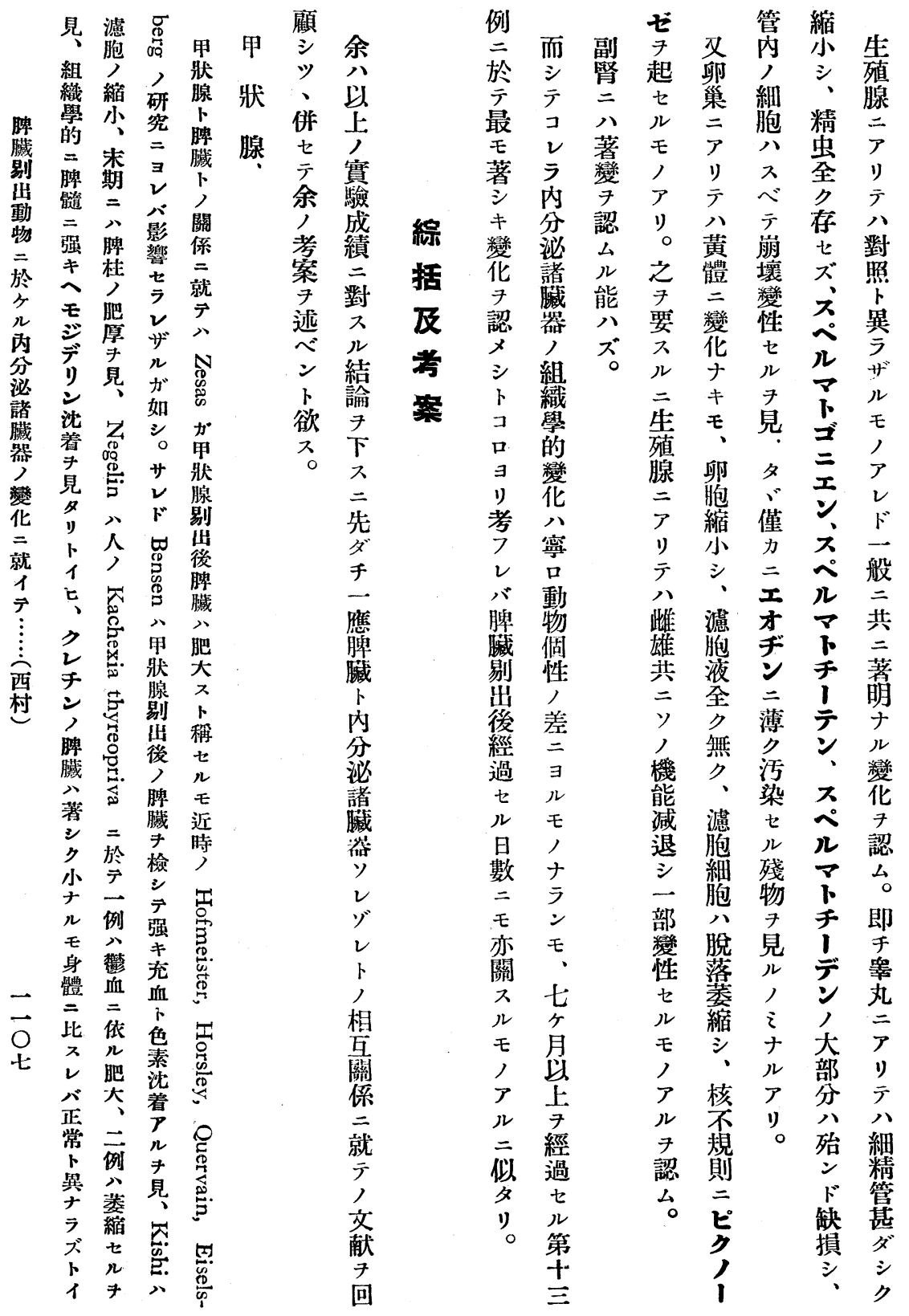




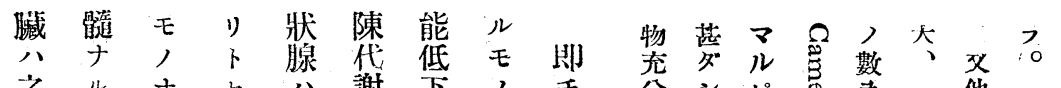

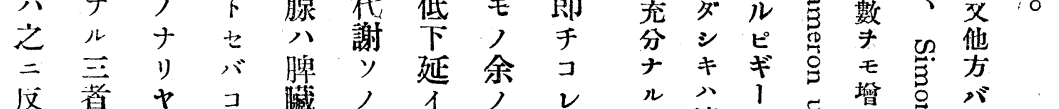

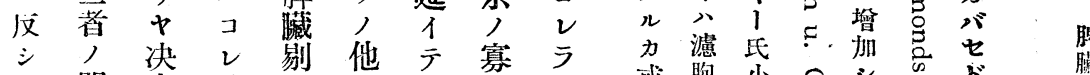

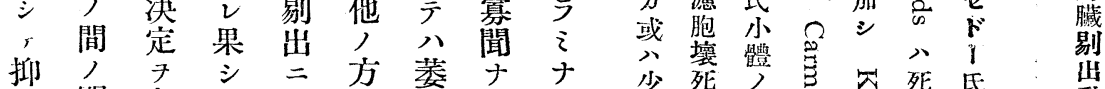

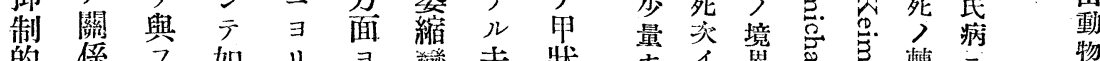

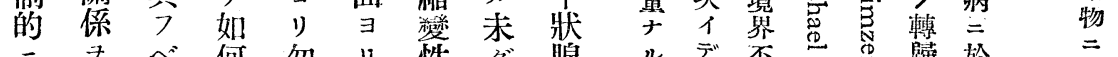

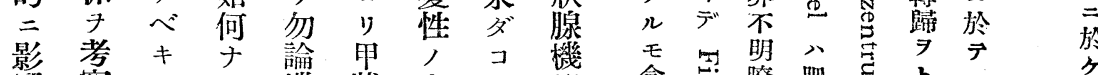
䇾 察 - 機 牀像し能 入入, 理能腺子ア海 ルル 根由克等呈ル長 モ二 據 基淮脾

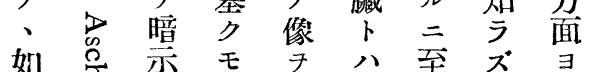

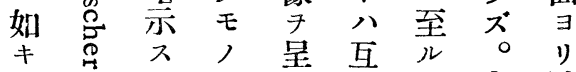

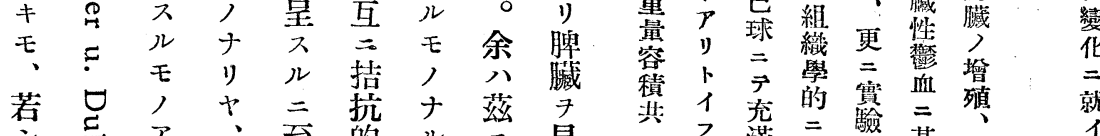
踪了、至的ル見

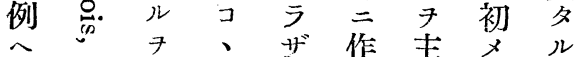

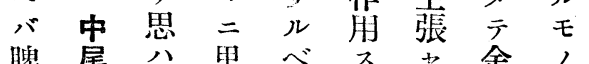

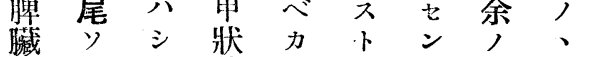
妇剔他台腺亏稳占寞さ

出含脾ルラ筬 シ

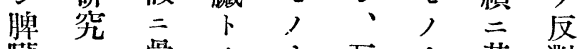
藏二骨, ナ互ナ基對

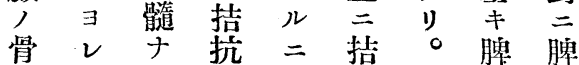

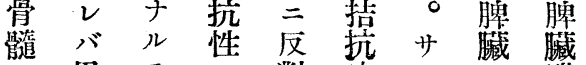
舁モ $尹$ 對的 對狀, 直二示 入腺 寻接機作覾出, 機骨令主熊角

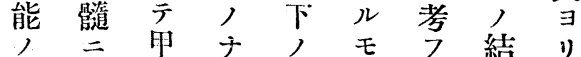

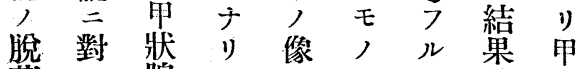
落 シ 腺 天 促: 將示》近曼腺

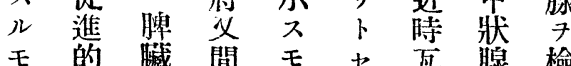
モ的藏閔モ 


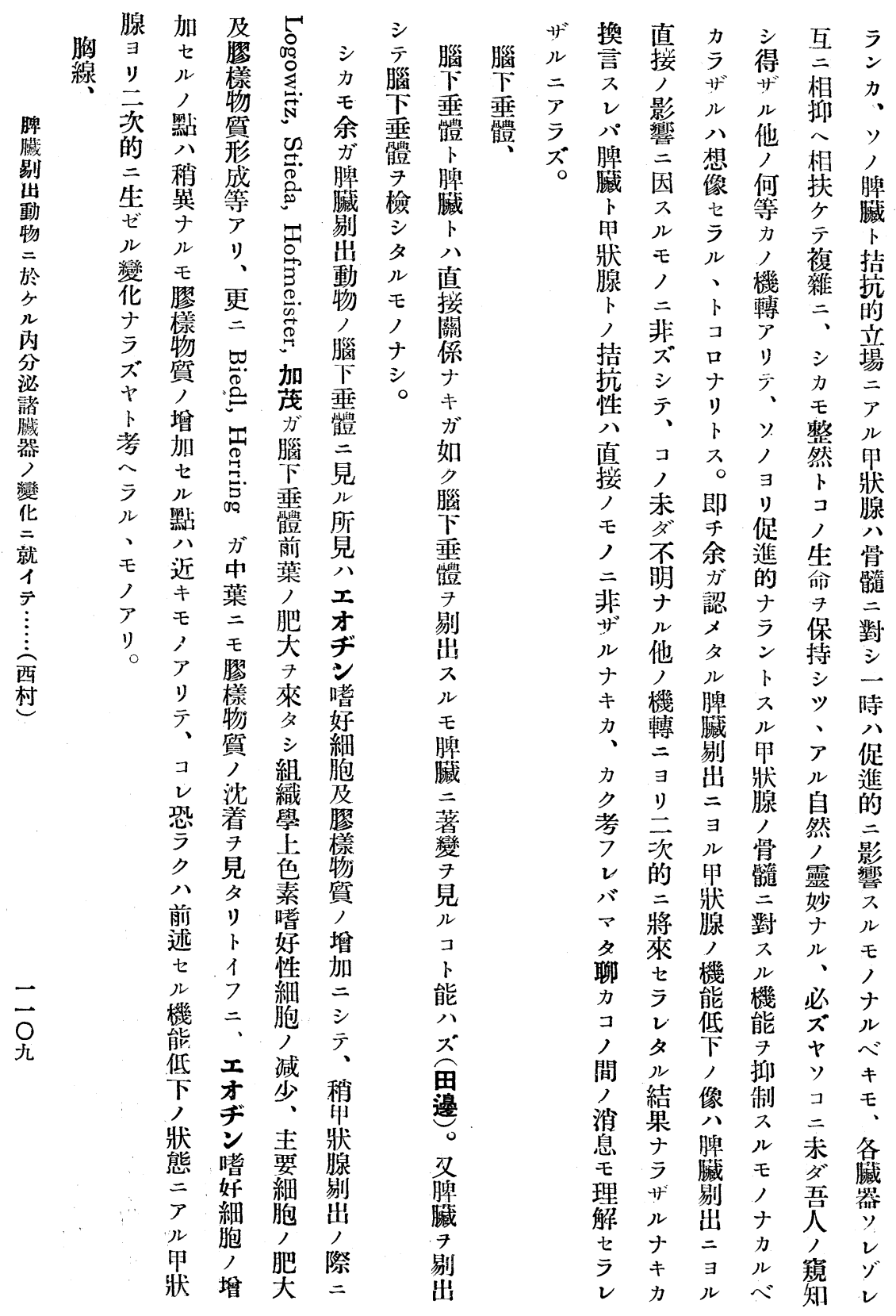




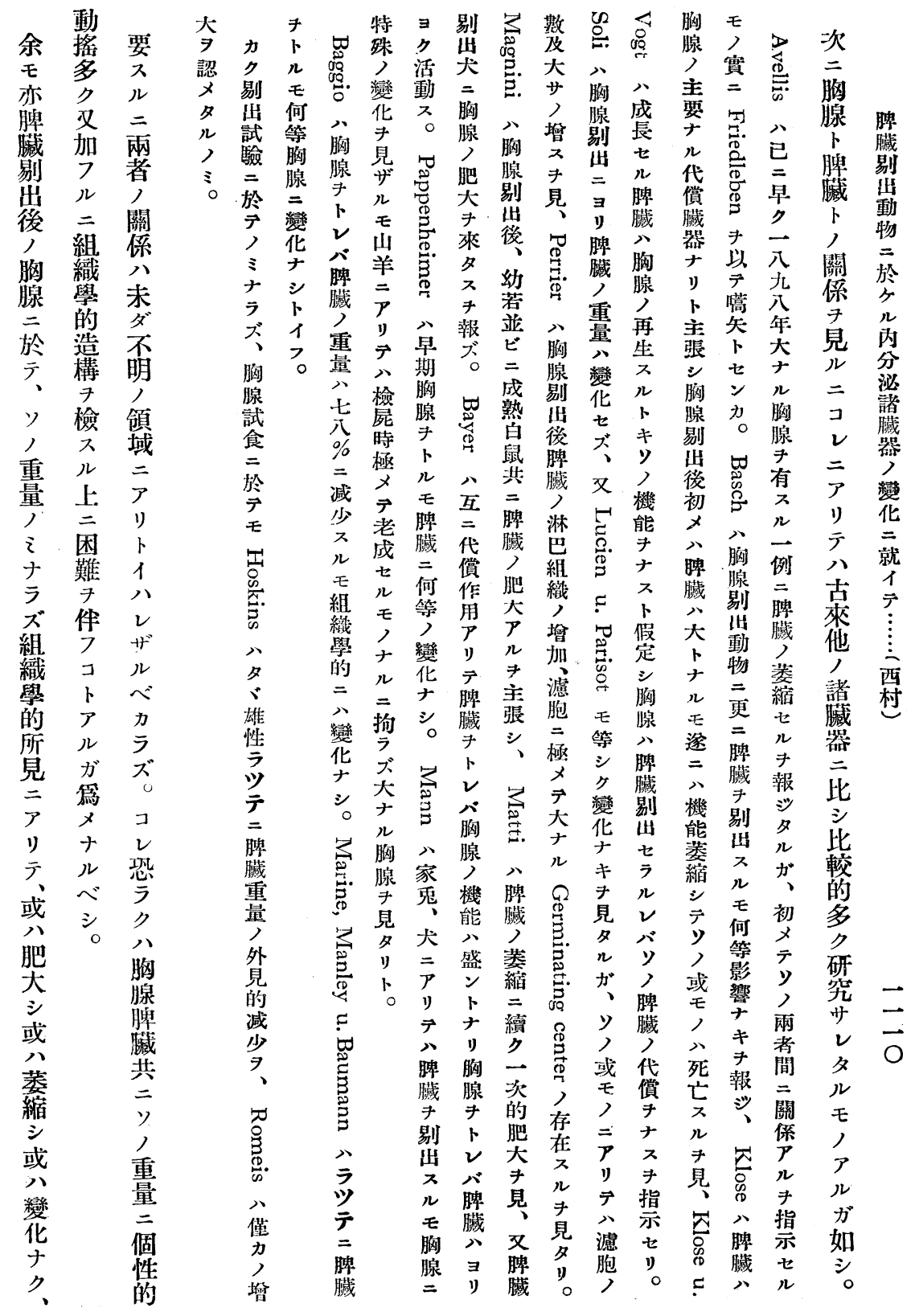




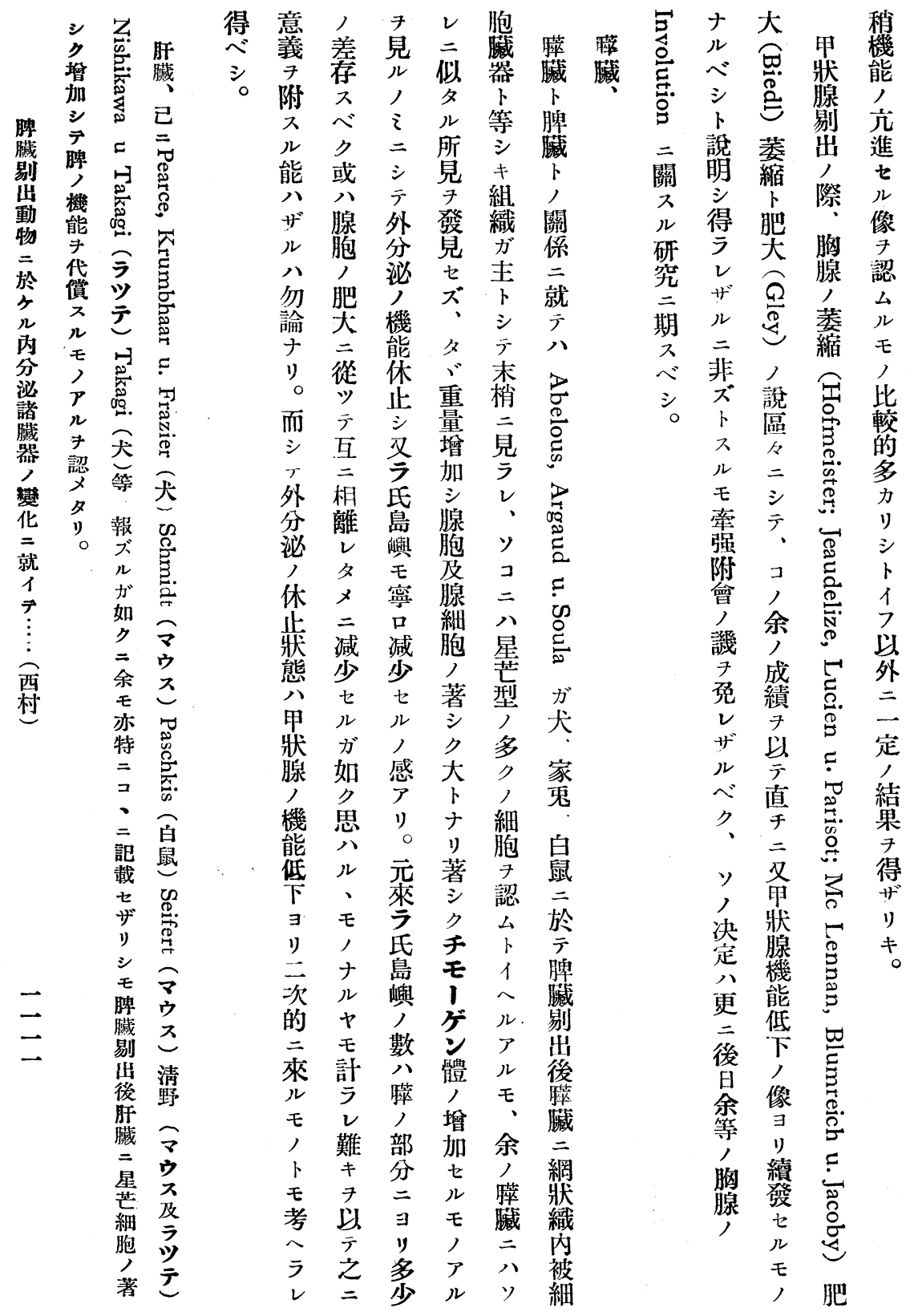




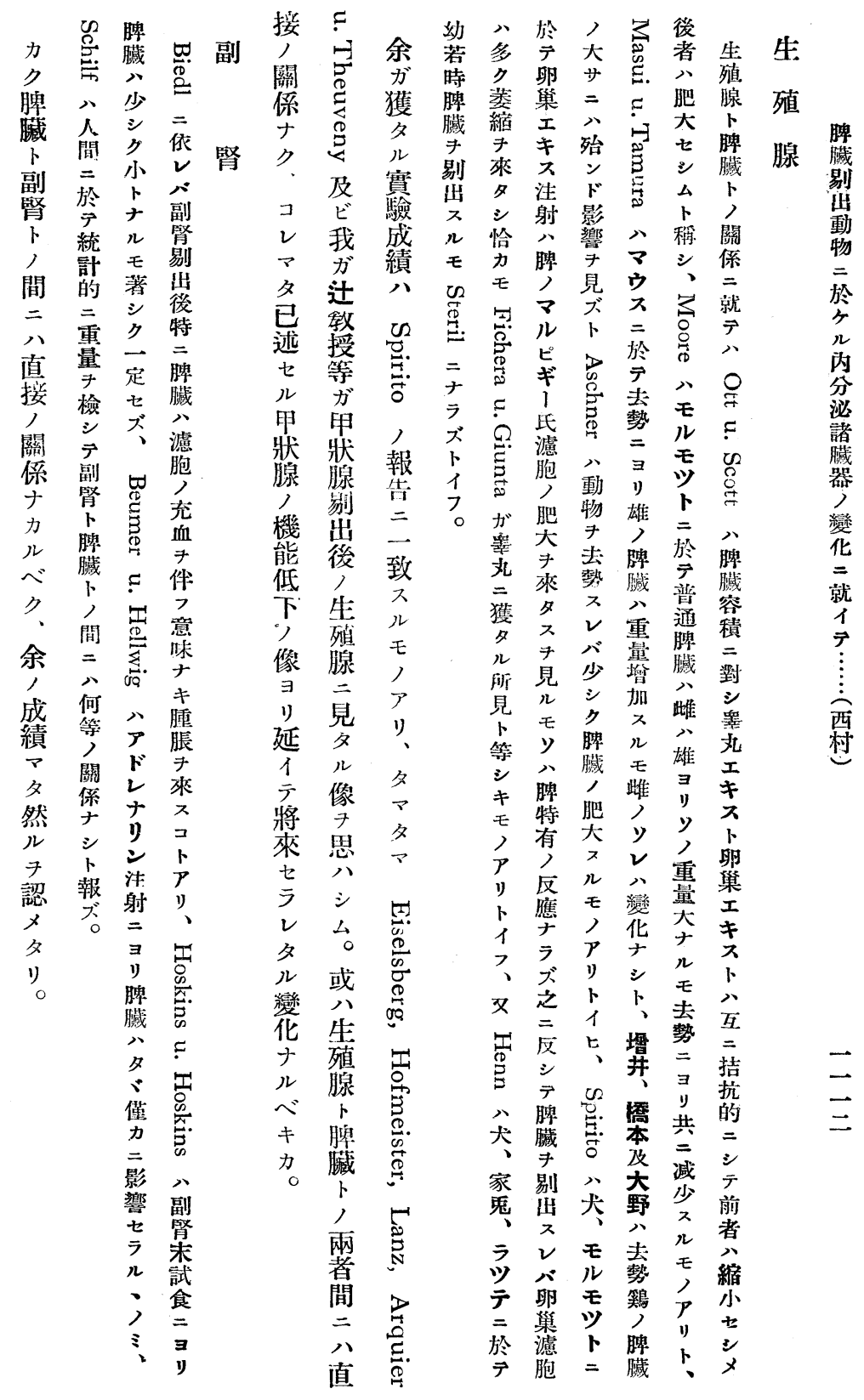




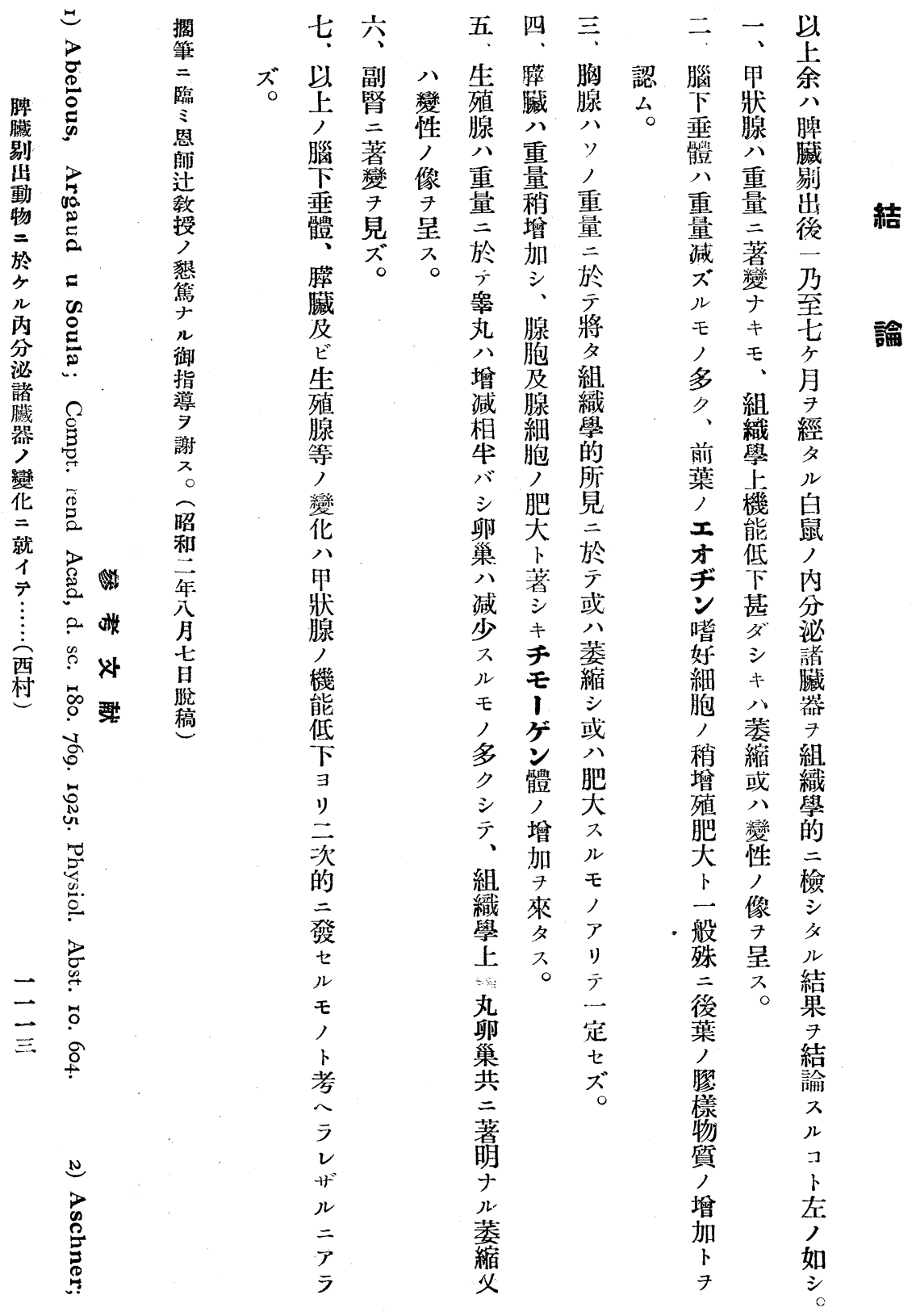




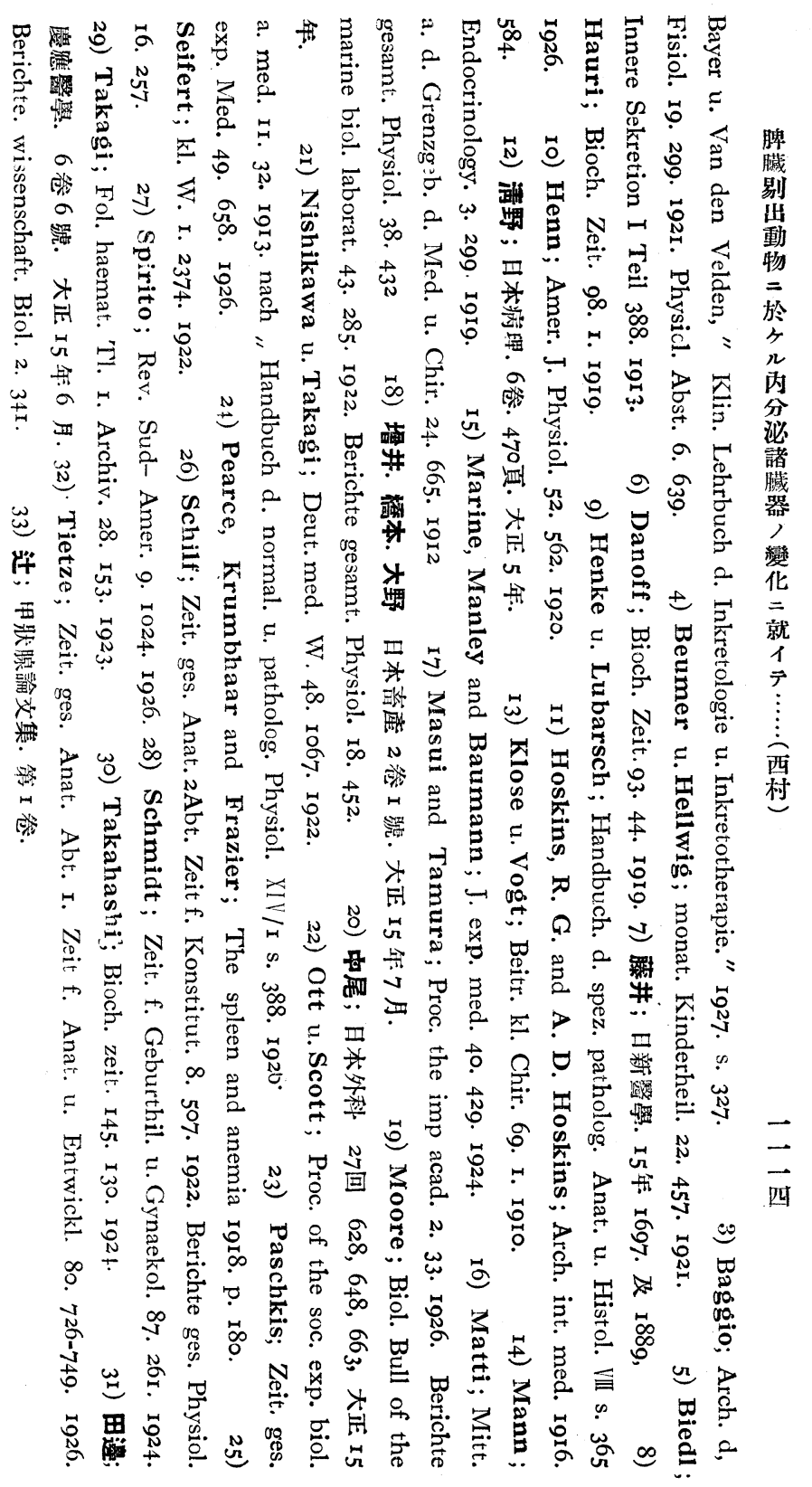



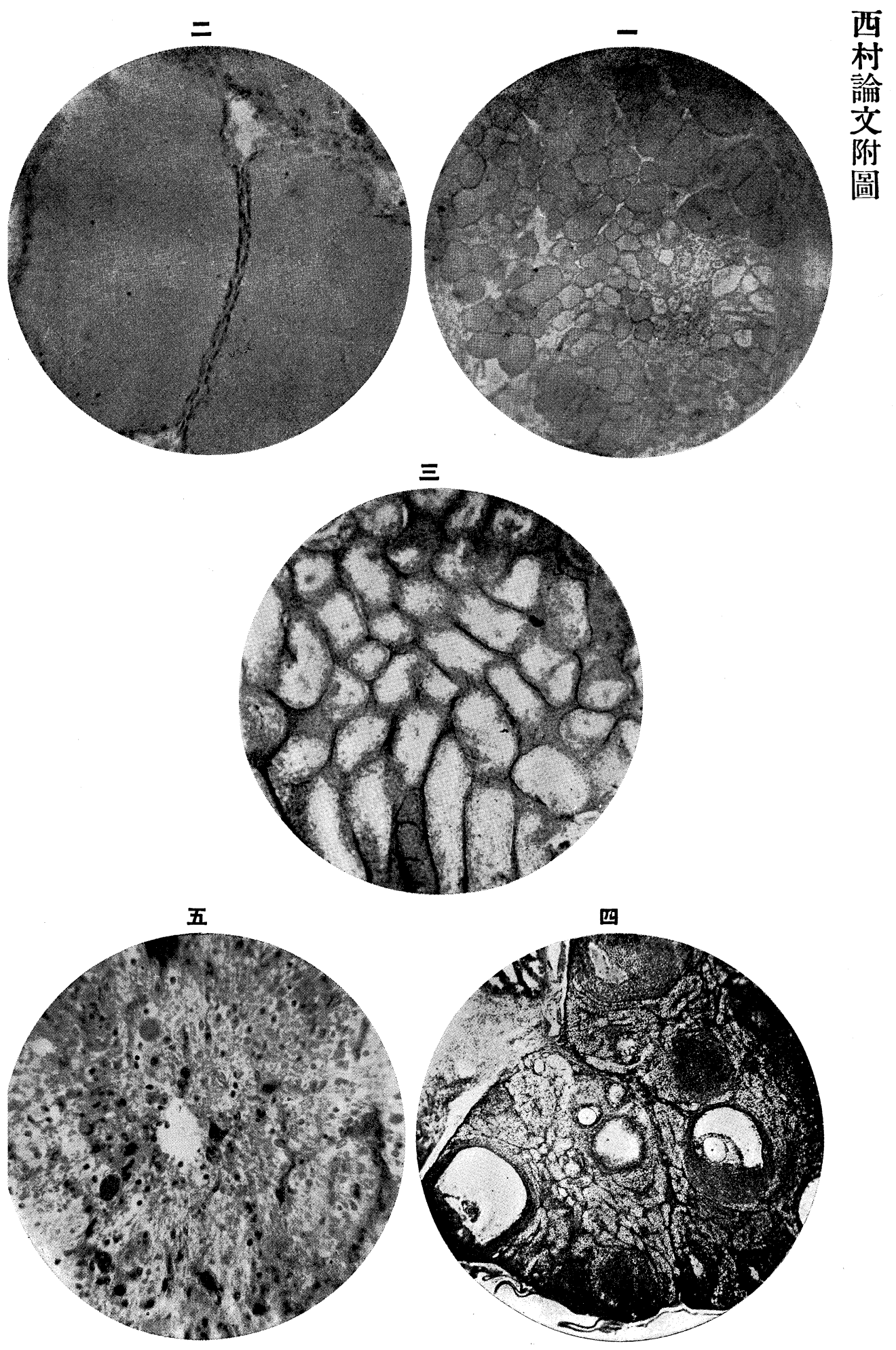


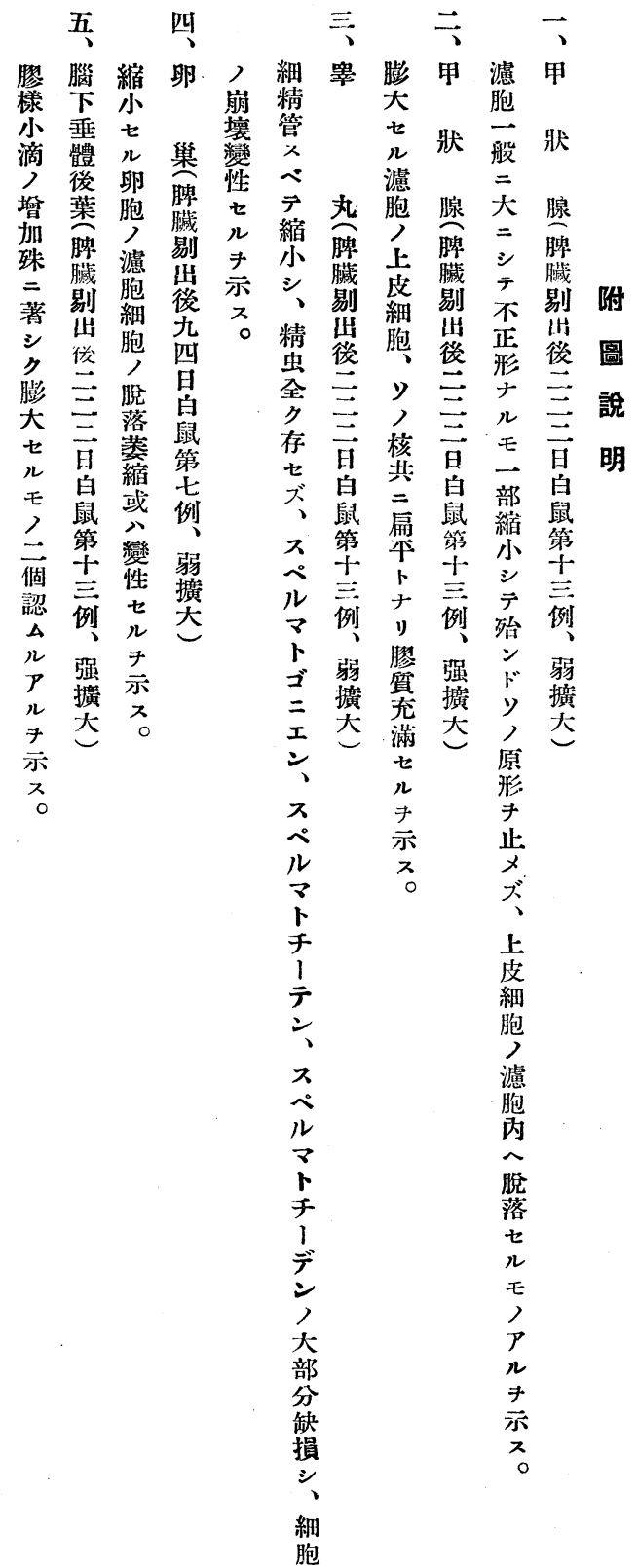


Mitteilung, die im nächsten Heft erscheinen soll) werden von der Atropininjektion gar nicht beeinflusst.

5) Das to $\%$ ige cholinfreie Nebennierenrindenextrakt übt nur selten einen Einfluss auf den Blutzucker aus, auf Insulin wirkt es aber synergisch und gegen Adrenalin antagonistisch. Diese Wirkungen vom cholinfreien Rindenextrakt sind zwar schwächer als die des kompletten Nebennierenrindenextrakts, lassen sich aber in den meisten Fällen sicher nachweisen.

6) Die Wirkung dieses cholinfreien Extrakts wird von Atropin gar nicht beeinflusst.

7) Wie oben erwähnt, zeigt die Injektion von grossen Mengen Cholins dem Nebennierenrindenextrakt nahe stehende Wirkungen, aber diese Cholinwirkungen werden durch Atropin völlig gehemmt.

Danach sind die Wirkungen des Nebennierenrindenextrakt nicht auf das Cholin, sondern auf das Extrakt selbst zurückzuführen.

(Autoreferat.)

\section{UEBER DIE HISTOLOGISCHEN VERÄNDERUNGEN DER INNERSEKRETORISCHEN ORGANE BEI DEN SPLENEKTOMIERTEN RATTEN.}

\section{Von}

Dr. S. Nishimura.

(Aus der I. med. Klinik der kaiserl. Univers. zu Kyoto. Direktor: Prof. Dr. K. Tsuji.)

$\mathbf{U}_{m}$ die Beziehung zwischen der Milz und den verschiedenen endokrinen Organen zu studieren, untersuchte der Verfasser histologisch die Befuude an den innersekretorischen Organen von Ratten, die I-7 Monate nach Splenektomie getötet wurden. Die Resultate waren die folgenden : 
I) Das Gewicht der Schilddrüse war normal. Sie zeigte aber das Bild der Kolloidstruma, nämlich das der Hypofunktion.

2) Die Hypophysis wies Vermehrung des Gewichts auf. Histologisch waren die eosinophjlen Zellen in den Vorderlappen vergrössert und an Zahl vermehrt, und weiter hatte die Kolloidsubstanz im allgemeinen, besonders in den Hinterlappen, zugenommen.

3) Das Gewicht der Bauchspeicheldrüse war etwas vermehrt, und in derselben fand sich Ansammlung des äussersekretorischen Drüsensekrets.

4) Das Gewicht des Hodens war teils vermehrt, teils vermindert und das des Ovariums meistens vermindert, aber die beiden Geschlechtsdrüsen zeigten deutlich das Bild von Atrophie und Degeneration.

5) Die Thymusdrüse und die Nebenniere zeigten keine nennenswerten histologischen Veränderungen.

6) Die oben erwähnten Veränderungen der Hypophysis, des Pankreas und der Geschlechtsdrüsen sind vielleicht sekundärer Natur, wie man sie bei der Hypofunktion der Schilddrüse antrifft.

(Autoreferat.)

\section{UEBER DEN EINFLUSS DER AUSSENTEMPERATUR \\ AUF DIE GEWEBSATMUNG.}

\section{Von}

Dr. M. Maeda.

(Aus der I. med. Klinik der kaiserl. Univers. zu Kyoto, Japan.

Direktor : Prof. Dr. K. Tsuji.)

Mittelst des Barcroftschen Manometers bestimmte der Verfasser die Gewebsatmung verschiedener Organe von Tauben, die bei erhöhter oder erniedrigter Aussentemperatur gehalten wurden. 